\title{
Detection of Middle East respiratory syndrome coronavirus using reverse transcription loop-mediated isothermal amplification (RT-LAMP)
}

Kazuya Shirato ${ }^{1 *}$, Takuya Yano ${ }^{2}$, Syouhei Senba ${ }^{3}$, Shigehiro Akachi², Takashi Kobayashi², Takamichi Nishinaka², Tsugunori Notomi ${ }^{3}$ and Shutoku Matsuyama ${ }^{1}$

\begin{abstract}
Background: The first documented case of Middle East Respiratory Syndrome coronavirus (MERS-CoV) occurred in 2012, and outbreaks have continued ever since, mainly in Saudi Arabia. MERS-CoV is primarily diagnosed using a real-time RT-PCR assay, with at least two different genomic targets required for a positive diagnosis according to the case definition of The World Health Organization (WHO) as of 3 July 2013. Therefore, it is urgently necessary to develop as many specific genetic diagnostic methods as possible to allow stable diagnosis of MERS-CoV infections.

Methods: Reverse transcription-loop-mediated isothermal amplification (RT-LAMP) is a genetic diagnostic method used widely for the detection of viral pathogens, which requires only a single temperature for amplification, and can be completed in less than $1 \mathrm{~h}$. This study developed a novel RT-LAMP assay for detecting MERS-CoV using primer sets targeting a conserved nucleocapsid protein region.

Results: The RT-LAMP assay was capable of detecting as few as 3.4 copies of MERS-CoV RNA, and was highly specific, with no cross-reaction to other respiratory viruses. Pilot experiments to detect MERS-CoV from medium containing pharyngeal swabs inoculated with pre-titrated viruses were also performed. The RT-LAMP assay exhibited sensitivity similar to that of MERS-CoV real-time RT-PCR.
\end{abstract}

Conclusions: These results suggest that the RT-LAMP assay described here is a useful tool for the diagnosis and epidemiologic surveillance of human MERS-CoV infections.

Keywords: Meddle East respiratory syndrome (MERS), MERS coronavirus (MERS-CoV), RT-LAMP, Genetic diagnostic method

\section{Background}

On 22 September 2012, a novel coronavirus sequence was detected from a 49-year-old patient presenting with severe pneumonia who was initially treated in an intensive care unit in Qatar and then moved to London [1]. The sequence of the PCR amplicon of this isolate was a close match with that of a coronavirus isolated from a 60-year-old patient who had died of severe pneumonia in Jeddah, Saudi Arabia in June 2012 [1,2]. Together, these two cases marked the beginning of an outbreak of

\footnotetext{
* Correspondence: shirato@nih.go.jp

'Laboratory of Acute Respiratory Viral Diseases and Cytokines, Department of Virology III, National Institute of Infectious Disease, Laboratory of Acute Respiratory Viral Diseases and Cytokines, 4-7-1 Gakuen, Musashimurayama, Tokyo 208-0011, Japan

Full list of author information is available at the end of the article
}

severe respiratory infections caused by a newly identified coronavirus, designated the Middle East Respiratory Syndrome coronavirus (MERS-CoV) [3]. This outbreak is ongoing, with 836 confirmed cases to date that have resulted in 288 deaths in 19 countries (Jordan, Qatar, Saudi Arabia, the United Arab Emirates, Oman, Kuwait, Yemen, Lebanon, Iran, Algeria, Tunisia, France, the Netherlands, Germany, the United Kingdom, Greece, Malaysia, Philippines and the United States of America) as of 14 July, 2014 [The World Health Organization (WHO), Global Alert and Response (GAR), Coronavirus infections, updated on 14 July 2014, http://www.who. $\mathrm{int} / \mathrm{csr} /$ disease/coronavirus_infections/en/index.html].

Sequence analyses show that MERS-CoV clusters with the group $2 \mathrm{c}$ betacoronavirus, and is closely related to 
the bat coronaviruses HKU4 and HKU5 [4]. Severe acute respiratory syndrome coronavirus (SARS-CoV), which caused severe pneumonia resulting in 8,098 reported infections and 774 deaths between 2002 and 2003 [5], was also derived from bat coronaviruses [6,7]. MERS-CoV, with its similar symptoms and phylogeny, is therefore considered a cousin of SARS-CoV. The reservoir for MERS$\mathrm{CoV}$ remains unclear, but recent reports suggest that camels are the most likely candidate, as a form of the virus has been circulating in camels in Saudi Arabia since at least 1992 [8-13].

MERS-CoV is primarily diagnosed using a real-time RT-PCR assay, and at least two different genomic targets are required for a positive diagnosis. The first probe and primer sets for MERS-CoV detection by real-time PTPCR were developed by Corman et al. shortly following the first reports of the disease $[14,15]$. Among them, the probe and primer sets targeting upE and ORF1a exhibit the highest sensitivities, and remain the most widely used targets for MERS-CoV detection. At least two different specific genomic targets are required for a positive diagnosis according to the case definition announced by the WHO as of 3 July 2013 [WHO, GAR, Revised interim case definition for reporting to WHO - Middle East respiratory syndrome coronavirus (MERS-CoV), updated on 3 July 2013, http://www.who.int/csr/disease/corona virus_infections/case_definition/en/index.html]. A single positive target followed by gene sequencing is also considered positive; however, the current gene sequencing technique requires PCR amplicons, and the ability of conventional RT-PCR to produce a sequencing-quality template is generally lower than that of real-time RTPCR [16-20]. Therefore, it is urgently necessary to develop as many specific genetic diagnostic methods as possible to allow reliable diagnosis of MERS-CoV infections.

The loop-mediated isothermal amplification (LAMP) method amplifies specific nucleic acid sequences using a set of four or six unique primers [21,22]. The LAMP procedure is user-friendly, since the reaction mixture is incubated at a single temperature for less than $1 \mathrm{~h}$. Amplification can be detected as the precipitation of magnesium pyrophosphate or by fluorescence under ultra-violet light, and also can be detected in real time by monitoring the turbidity of the pyrophosphate [23]. The LAMP assay can also be used for the detection of RNA by combining reverse transcription with LAMP (RT-LAMP) [21]; RT-LAMP assays have been developed for a variety of respiratory RNA viruses, including SARS [24], respiratory syncytial virus $[25,26]$, and influenza viruses $[27,28]$. In this study, a novel RT-LAMP method for the detection of MERS-CoV was developed, with a sensitivity similar to that of real-time RT-PCR targeting upE and ORF1a.

\section{Materials and methods Viruses}

The MERS-CoV EMC isolate was kindly provided by Ron A. M. Fouchier, Erasmus Medical Center, Rotterdam, The Netherlands. MERS-CoV was propagated and titrated using Vero cells. Human respiratory syncytial viruses (RSV; Long, A2, B WV/14617/85 and 18537) were obtained from the American Tissue Culture Collection (ATCC). Human metapneumovirus (HMPV; Sendai-H/ 2404/2003) was obtained from the Virus Research Center, Sendai Medical Center, Japan. Human coronavirus (HCoV)-229E isolates ATCC VR-740 and Sendai-H/1121/ 04 [29] were used. HCoV-NL63 was supplied by Dr. Hoek, University of Amsterdam, Netherlands. Isolate $\mathrm{HCoV}$ OC43 was obtained from ATCC. SARS coronavirus (Frankfurt strain) was supplied by Dr. J. Ziebuhr, University of Würzburg, Germany. Human parainfluenza viruses (PIV) 1 (strain C35) and 3 (strain C243) were obtained from ATCC. Adenoviruses (ADV) (serotype 3, strain G.B.; serotype 4, strain RI-67; and serotype 7, strain Gomen) were obtained from ATCC. Viruses were propagated and titrated using HEp-2, HeLa, RD, Vero cells, or LLC-Mk2 cells [30]. Influenza viruses [Flu; A/California/7/2009 (H1N1pdm), A/Victoria/210/ 2009 (H3N2), and B/Brisbane/60/2008] were provided by the Influenza Virus Research Center of the National Institute of Infectious Diseases in Japan, and were propagated and titrated using MDCK cells.

\section{Design of primer sets for RT-LAMP}

Primer sets for the RT-LAMP assay were designed using the online LAMP primer design software (PrimerExplorer V4; http://primerexplorer.jp/e/) based on the nucleocapsid protein sequence of the EMC isolate of MERS-CoV (GenBank JX869059.2).

\section{Extraction of nucleic acids}

RNA was extracted from viral stocks using TRIzol LS or TRIzol reagent (Invitrogen), according to the manufacturer's instructions. Viral DNA was extracted using Qiagen Genomic-tip (Qiagen, Hilden, Germany), according to the manufacturer's instructions. Total RNA and genomic DNA were quantitated using standard methods to measure the OD value. The MERS-CoV RNA copy number was calculated based upon the standard curve obtained using a TaqMan assay, as described by Corman et al. [14] (upE probe set and the positive control template). Total RNA was then diluted with ribonuclease-free water containing $10 \mu \mathrm{g} / \mathrm{mL}$ of Ribonucleic Acid from Baker's Yeast (R6750; Sigma-Aldrich, St. Louis, MO, USA) as carrier RNA.

\section{RT-LAMP assay}

The RT-LAMP assay was performed using the Loopamp RNA Amplification Kit (RT-LAMP; Eiken, Tokyo, Japan) 
under the following conditions: $5-\mu \mathrm{L}$ sample (RNA or DNA) was mixed with 40 pmol each of FIP and BIP primers, 20 pmol each of LF and LB primers, 5 pmol each of F3 and B3 primers, 1- $\mu \mathrm{L}$ Enzyme Mix, and 12.5- $\mu \mathrm{L}$ Reaction Mix; distilled water was added to obtain a final volume of $25 \mu \mathrm{L}$. For real-time monitoring of RT-LAMP amplification, the reaction mixture was incubated at $65^{\circ} \mathrm{C}$ for $30 \mathrm{~min}$ in a Loopamp real-time turbidimeter (LA320C, Eiken). For fluorescence detection, 1- $\mu \mathrm{L}$ Fluorescent Detection Reagent (Eiken) was added to the reaction mixture described above before the start of amplification, and then, fluorescence was detected under ultraviolet light after 30 min of amplification. Negative controls containing only yeast RNA were included in each assay.

To synthesize control RNA for RT-LAMP, the nucleocapsid protein sequence of the EMC strain (2856629807) was amplified and cloned into the pGEM-T easy vector (Promega, Fitchburg, WI, USA). Point mutations were inserted using a site-direct mutagenesis technique to generate variations of the nucleoprotein sequence. The nucleocapsid protein sequence was amplified by PCR using forward (5' -TAATACGACTCACTATAGG GATGGCATCCCCTGCTGCACC-3') and reverse (5'CTAATCAGTGTTAACATCAA-3') primers with PrimeSTAR Max DNA polymerase (Takara-Bio, Shiga, Japan). The amplicons were gel-purified and were used as templates for RNA transcription using a MEGAscript T7 Transcription Kit (Life Technologies, Carlsbad, CA, USA). The transcribed RNA was quantified using the OD value, the copies number was calculated, and the RNA was diluted with ribonuclease-free water containing $10 \mu \mathrm{g} / \mathrm{mL}$ of yeast RNA.

\section{Real-time RT-PCR assays}

Real-time RT-PCR assays using upE and ORF1a sets $[14,15]$ were also performed for virus detection using a QuantiTect Probe RT-PCR kit (QIAGEN) and LightCycler 480 Instrument (Roche, Basel, Switzerland) following the manufacturers' protocols. The amplification conditions followed Corman et al. $[14,15]$.

\section{Virus preparation for spiked samples}

For sensitivity assays, Vero cells were infected with MERS$\mathrm{CoV}$, and incubated for 4 days. Cell supernatants were then collected and centrifuged at $1,500 \times \mathrm{g}$ for $30 \mathrm{~min}$ at $4^{\circ} \mathrm{C}$, and the supernatants were treated with RNaseA (Nippongene, Tokyo Japan) at a concentration of $10 \mu \mathrm{g} / \mathrm{mL}$ for $30 \mathrm{~min}$ at $37^{\circ} \mathrm{C}$ to exclude miscellaneous RNA other than viral RNA.

\section{Pilot experiment}

MERS-CoV RNA was obtained from pre-titrated viral stocks diluted with medium containing pharyngeal swabs obtained from healthy adults using the Universal Viral
Transport for Viruses, Chlamydiae, Mycoplasmas and Ureaplasmas (Becton Dickinson and Company, Sparks, MD, USA). Viral isolation was also performed on Vero and Vero/TMPRSS2 cells constitutively expressing type II transmembrane serine protease (TMPRSS2) [30], which enhances cell entry and fusion formation of MERS-CoV $[31,32]$. Diluted viruses were inoculated on Vero and Vero/TMPRSS2 cells, and incubated for $60 \mathrm{~min}$. Cells were then washed with PBS, and incubated in Dulbecco's modified Eagle's medium supplemented with 5\% fetal calf serum at $37^{\circ} \mathrm{C}$. The cytopathic effect was evaluated 5 days after inoculation. Clinical specimens (nasopharyngeal swabs) diagnosed as other respiratory pathogens by RTPCR assays were used as negative controls. Informed, written consent was obtained at the time of sample collection from all patients. For the specimen diagnosed as human bocavirus, a LAMP assay was performed without the RT reaction.

\section{Results}

\section{RT-LAMP primer design}

The primer sets used in this study are listed in Table 1. RT-LAMP requires at least six specific sequences (F1, F2, F3, B3, B2, and B1), targeted by a minimum of four distinct primer sets. Two loop primers (LF and LB) are used to enhance amplification [22]; these primers target the regions between F1 \& F2, and B1 \& B2 regions, respectively. Generally, the reaction of RT-LAMP is performed for $1 \mathrm{~h}$. However, the primers described here tend to generate products of self-construction because these were constructed to enhance the sensitivity of amplification. Therefore, the reaction was performed within $30 \mathrm{~min}$ to exclude non-specific reactions. It was confirmed that non-specific amplification did not take place within 30 min using negative control samples (data not shown).

\section{Sensitivity and specificity of the RT-LAMP assay}

The detection limit of the RT-LAMP assay was determined using serially diluted MERS-CoV, and compared with those of real-time RT-PCR using upE and ORF1a assays [14,15] (Table 2). upE and ORF1a assays were able to detect 1.6 to 3.4 copies of MERS-CoV RNA, consistent with previous reports. The threshold for RT-LAMP within $30 \mathrm{~min}$ was also 3.4 copies, indicating a sensitivity equivalent to that of real-time RT-PCR $[14,15]$.

RT-LAMP amplification can be monitored in three DNA contamination-free manners. First is a real-time method that monitors the turbidity of the pyrophosphate precipitation using a turbidimeter (LA-320C) (Figure 1a). The differentiated value of each signal is calculated automatically at the same time during amplification, with values $>0.1$ considered positive. RT-LAMP can also detect MERS-CoV without any specific instruments by detecting visible signals at the same level as real-time 
Table 1 The primer set for MERS-CoV RT-LAMP assay

\begin{tabular}{lllc}
\hline Primers & Position (EMC, JX869059.2) & Sequence $\mathbf{( 5}^{\prime} \mathbf{-} \mathbf{3}^{\prime}$ ) & Number of matched MERS sequences* \\
\hline F3 & $28848-28866$ & GCTCCCAGGTGGTACTTCT & $86 / 88$ \\
B3 & $29061-29042$ & cagtcccctcaatgtggaag & $88 / 88$ \\
FIP (F1C + F2) & $28939-28918$ & tcatggacccaaacgatgccatACTGGAACTGGACCCGAAG & $77 / 88$ \\
& $+28872-28890$ & & $88 / 88$ \\
BIP (B1C + B2) & $28956-28977$ & GCTCCTTCAACTTTTGGACGCtagtaccgggcgcgaatt & $87 / 88$ \\
& $+29028-29011$ & & $83-88$ \\
LF & $28906-28891$ & cggaatgggagtgctg & $88 / 88$ \\
LB & $28978-29000$ & GGAACCCTAACAATGATTCAGCT & $85 / 88$ \\
\hline
\end{tabular}

Capital letters indicate the sense strand; lowercase letters indicate the antisense strand.

*Eighty-one sequences were obtained from GenBank (JX869059, KJ829365, KJ813439, KJ713299, KJ713298, KJ713297, KJ713296, KJ713295, KJ650297, KJ650296, KJ650295, KJ650098, KJ556336, KJ477102, KJ156953, KJ156952, KJ156949, KJ156944, KJ156942, KJ156939, KJ156934, KJ156932, KJ156927, KJ156917, KJ156916, KJ156913, KJ156911, KJ156910, KJ156909, KJ156907, KJ156906, KJ156905, KJ156902, KJ156901, KJ156883, KJ156881, KJ156876, KJ156874, KJ156873, KJ156872, KJ156871, KJ156869, KJ156866, KJ156865, KJ156862, KJ156861, KF961222, KF961221, KF958702, KF917527, KF811035, KF745068, KF600652, KF600651, KF600647, KF600645, KF600644, KF600643, KF600639, KF600636, KF600635, KF600634, KF600632, KF600630, KF600628, KF600627, KF600623, KF600621, KF600620, KF600613, KF600612, KF192507, KF186567, KF186566, KF186565, KF186564, KC875821, KC776174, KC667074, KC164505, and KJ782550) and seven sequences were obtained online (England2-HPA, http://www.hpa.org.uk/webc/HPAwebFile/HPAweb_C/1317138176202: Jeddah_2014_C7149, C7569, C7770, C8826, C9055, and C9355, http://www.virology-bonn.de/index.php?id=46).

monitoring. Amplification can be determined through visual detection of magnesium pyrophosphate precipitation following completion of the reaction (Figure 1b). Furthermore, amplicons can be detected by means of green fluorescence under ultraviolet light by adding a fluorescence detection reagent to the mixture before the start of amplification (Figure 1c).

In addition to MERS-CoV, specific amplification via RT-LAMP was also tested using various respiratory viruses (Table 3). RT-LAMP was performed using pretitrated viral stocks, as well as clinical specimens previously validated by PCR. MERS-CoV RT-LAMP was specific for MERS-CoV; other respiratory viruses, such as HCoV, SARS-CoV, RSV, influenza, PIV, ADV, and HMPV could not be amplified using the MERS-CoV primers.

\section{Pilot experiments}

As MERS-CoV clinical isolates are not available in Japan, a pilot study was performed using MERS-CoV laboratory isolates diluted with medium containing pharyngeal swabs obtained from healthy adults. Viral detection was carried out using both RT-LAMP and real-time RT-PCR assays, and with virus isolation using Vero and Vero/
TMPRSSS2 cells (Table 4). Viral isolation from Vero cells required at least 500 copies of MERS-CoV, followed by incubation at $37^{\circ} \mathrm{C}$ for 5 days. It contrast, although it has been reported that TMPRSS2 enhances the entry and fusion formation of MERS-CoV [31,32], Vero/TMPRSS2 cells exhibited syncytium formation with 23.2 copies of MERS-CoV within 2 days of incubation.

The real-time RT-PCR was highly sensitive for MERS$\mathrm{CoV}$, with upE and ORF1a assays capable of detecting as few as 1.6 copies of MERS-CoV RNA. The RT-LAMP was also able to detect viral RNA at levels as low as 0.7 copies, showing equivalence with the RT-PCR assay. Viral isolation using Vero/TMPRSS2 cells was more sensitive than that of Vero cells; however, genetic diagnostic assays were consistently more sensitive than culturebased methods. These data suggest that the RT-LAMP assay is capable of detecting MERS-CoV with a sensitivity similar to that of real-time-RT-PCR, even in clinical specimens.

Next, clinical specimens previously diagnosed as other respiratory pathogens were tested using the RT-LAMP assay (Table 5). All reactions were negative, with no cross reactivity for other respiratory viruses, indicating a high degree of specificity for the RT-LAMP assay. Collectively,

Table 2 Sensitivity of the RT-LAMP assay

\begin{tabular}{lccccccccc}
\hline Copies/reaction & $\mathbf{5 0 0 , 0 0 0}$ & $\mathbf{5 0 , 0 0 0}$ & $\mathbf{5 0 0 0}$ & $\mathbf{5 0 0}$ & $\mathbf{5 0}$ & $\mathbf{5}$ & $\mathbf{0 . 5}$ & Negative control & Sensitivity (copies) \\
\hline Real-time RT-PCR* & & & & & & & & & \\
upE & 21.2 & 24.4 & 27.9 & 31.3 & 34.2 & 36.6 & 40 & $>40$ \\
ORF1a & 21.6 & 24.4 & 27.6 & 30.4 & 32 & 31.8 & $>40$ & $>40$ & 3.4 \\
RT-LAMP** & 11.33 & 12.13 & 13.07 & 15.44 & 21.44 & 22.33 & $>30$ & 3.4 \\
\hline
\end{tabular}

*Threshold cycle.

**Time (min. s). 
a)
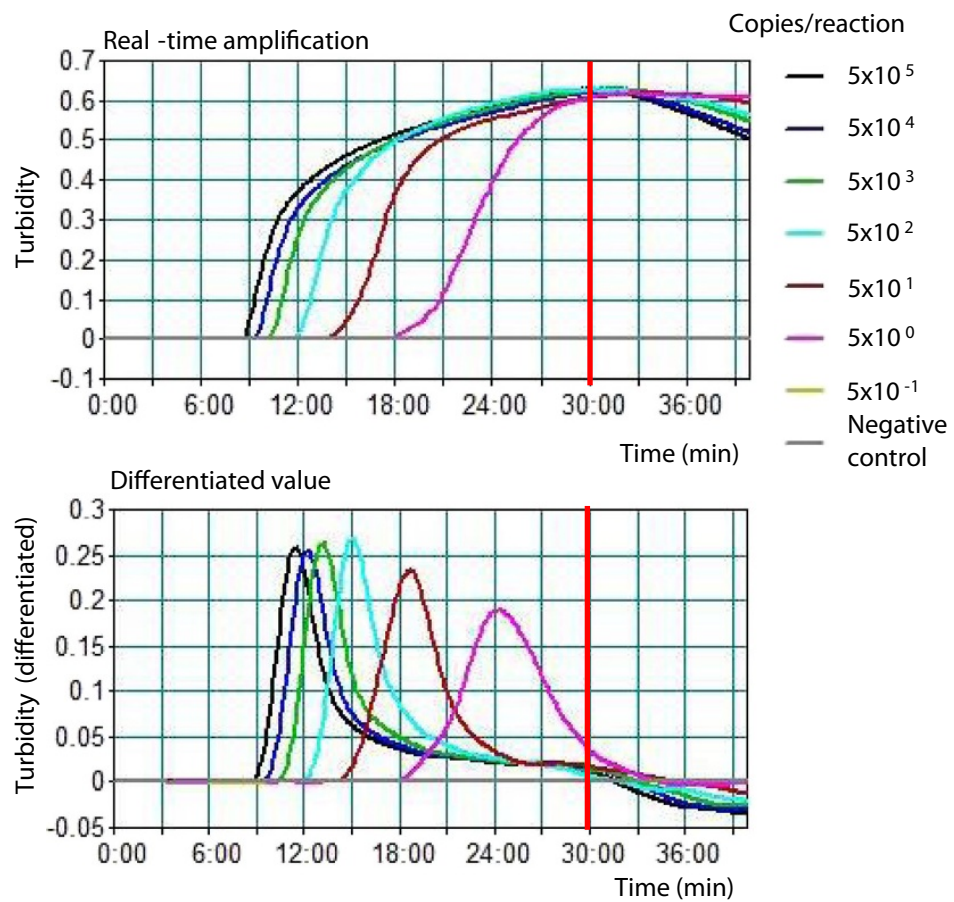

b)

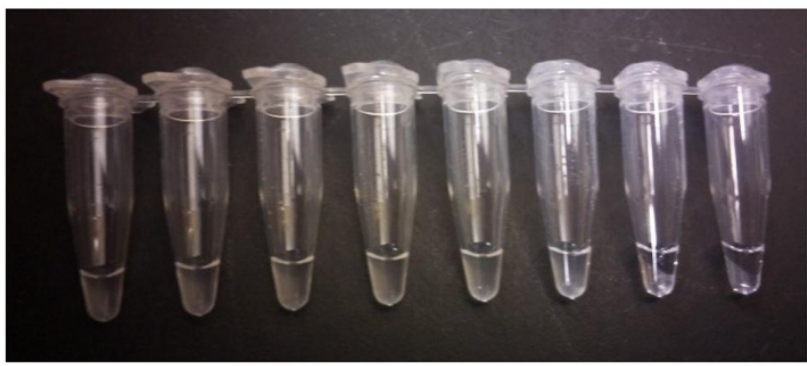

Copies /reaction

$\begin{array}{rrrrrr}5 \times 10^{5} & 5 \times 10^{4} & 5 \times 10^{3} & 5 \times 10^{2} & 5 \times 10^{1} \quad 5 \times 10^{0} \quad 5 \times 10^{-1} \begin{array}{l}\text { Negative } \\ \text { control }\end{array}\end{array}$

c)

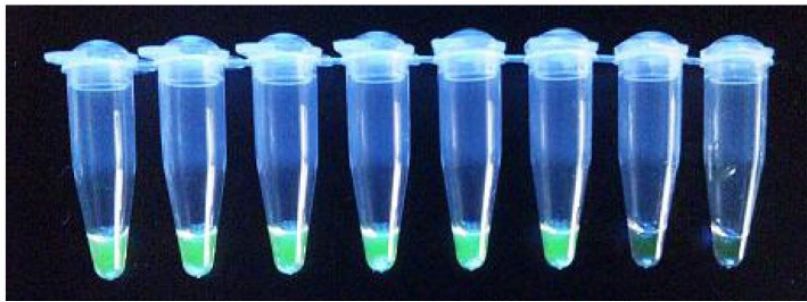

Copies

$5 \times 10^{5} 5 \times 10^{4} 5 \times 10^{3} 5 \times 10^{2} 5 \times 10^{1} 5 \times 10^{0} 5 \times 10^{-1}$ Negative /reaction control

Figure 1 Sensitivity of the MERS-CoV RT-LAMP assay. a) Real-time amplification of MERS-CoV by RT-LAMP. Amplification of serially diluted MERS-CoV RNA was measured in real-time using a Loopamp real-time turbidimeter (LA-320C). The differentiated value at each dilution was calculated automatically, with values $>0.1$ within 30 min (red line) considered positive. b, c) Detection of RT-LAMP amplicon by b) precipitation of magnesium pyrophosphate and c) fluorescence under ultra violet light. For fluorescence detection, 1- $\mu \mathrm{L}$ Fluorescence Detection Reagent was added to each reaction mixture. Fluorescent signals were detected under ultraviolet following completion of the amplification reaction. Successful amplification could be detected as green fluorescent light. 
Table 3 Specificity of the RT-LAMP assay

\begin{tabular}{|c|c|c|}
\hline Virus & Titer/reaction & Results (min) \\
\hline \multicolumn{3}{|l|}{ Coronaviruses } \\
\hline MERS-CoV (EMC) & $4 \times 10^{1} \mathrm{TCID}_{50}$ & 14.24 \\
\hline HCoV 229E (VR-740) & $3 \times 10^{3} \mathrm{PFU}$ & $>30$ \\
\hline HCoV 229E (Sendai-H/1121/04) & $5 \times 10^{3} \mathrm{PFU}$ & $>30$ \\
\hline HCoV NL63 & $2.5 \times 10^{2} \mathrm{FFU}$ & $>30$ \\
\hline HCoV OC43 (VR-1558) & $1.3 \times 10^{3} \mathrm{TCID}_{50}$ & $>30$ \\
\hline SARS-CoV (Frankfurt) & $1 \times 10^{5} \mathrm{PFU}$ & $>30$ \\
\hline \multicolumn{3}{|l|}{ Other Respiratory Viruses } \\
\hline RSV A (Long) & $1 \times 10^{1} \mathrm{PFU}$ & $>30$ \\
\hline RSV A (A2) & $1 \times 10^{2} \mathrm{PFU}$ & $>30$ \\
\hline RSV B (18537) & $1 \times 10^{2} \mathrm{PFU}$ & $>30$ \\
\hline RSV B (WV/14617/85) & 一 $^{*}$ & $>30$ \\
\hline HMPV (Sendai-H/2404/2003) & 一 $^{*}$ & $>30$ \\
\hline PIV 1 (C-35) & $3 \times 10^{4} \mathrm{PFU}$ & $>30$ \\
\hline PIV 3 (C-243) & $5 \times 10^{3} \mathrm{PFU}$ & $>30$ \\
\hline ADV 3 (G.B.) & $2.5 \times 10^{2} \mathrm{TCID}_{50}$ & $>30$ \\
\hline ADV 4 (RI-67) & $1 \times 10^{2} \mathrm{TCID}_{50}$ & $>30$ \\
\hline ADV 7 (Gomen) & $2.5 \times 10^{2} \mathrm{TCID}_{50}$ & $>30$ \\
\hline Flu A/California/7/2009 (H1N1 pdm) & $8 \times 10^{3} \mathrm{TCID}_{50}$ & $>30$ \\
\hline Flu ANictoria/210/2009 (H3N2) & $2.5 \times 10^{6} \mathrm{TCID}_{50}$ & $>30$ \\
\hline Flu B/Brisbane/60/2008 & $2.5 \times 10^{4} \mathrm{TCID}_{50}$ & $>30$ \\
\hline
\end{tabular}

*Titer unknown, but was confirmed by PCR.

PFU: plaque forming unit.

FFU: focus forming unit.

TCID50: 50\% tissue culture infectious dose.

these results suggest that the MERS-CoV RT-LAMP assay is useful for epidemiological surveillance in suspected clinical cases.

\section{RT-LAMP validation for mismatched sequences}

The primer set was constructed based on the conserved region of the nucleocapsid protein sequence of the EMC isolate of MERS-CoV (GenBank accession no JX869059.2).
Table 5 Detection of MERS-CoV using clinical specimens diagnosed as other respiratory viral infections

\begin{tabular}{|c|c|}
\hline Diagnosed pathogen & Results (min) \\
\hline \multicolumn{2}{|l|}{ Positive control } \\
\hline${ }^{*}$ MERS-CoV (10 $10^{4}$ copies) & 9.00 \\
\hline \multicolumn{2}{|l|}{ Coronaviruses } \\
\hline $\mathrm{HCOV}$ OC43 & $>30$ \\
\hline HCoV NL63 & $>30$ \\
\hline HCOV HKU1 & $>30$ \\
\hline \multicolumn{2}{|l|}{ Other Respiratory viruses } \\
\hline RSV A & $>30$ \\
\hline RSV B & $>30$ \\
\hline HMPV & $>30$ \\
\hline PIV 1 & $>30$ \\
\hline PIV 2 & $>30$ \\
\hline PIV 3 & $>30$ \\
\hline PIV 4 & $>30$ \\
\hline Rhinovirus & $>30$ \\
\hline Bocavirus & $>30$ \\
\hline Flu A H1 (Russian) & $>30$ \\
\hline Flu A H1 (2009 pdm) & $>30$ \\
\hline Flu A H3 & $>30$ \\
\hline Flu B (Yamagata) & $>30$ \\
\hline Flu B (Victoria) & $>30$ \\
\hline Flu C & $>30$ \\
\hline Measles virus & $>30$ \\
\hline Rubella virus & $>30$ \\
\hline
\end{tabular}

*Synthesized RNA obtained from $\mathrm{N}$ protein region.

The number of sequences deposited in GenBank is increasing, and this region of MERS-CoV exhibits several sequences variation. Therefore, the primer sequences were checked against the available MERS-CoV sequences. Eighty-one MERS-CoV nucleocapsid sequences were collected from GenBank, along with seven other sequences

Table 4 Detection of MERS-CoV diluted with medium containing pharyngeal swabs

\begin{tabular}{|c|c|c|c|c|c|c|c|c|c|c|}
\hline Copies/50 $\mu \mathrm{L}$ & 500,000 & 50,000 & 5000 & 500 & 50 & 5 & 0.5 & Negative control & Sensitivity (copies) & Time required \\
\hline \multicolumn{11}{|l|}{ Virus isolation* } \\
\hline Vero & $6 / 6$ & $6 / 6$ & $6 / 6$ & $3 / 6$ & $0 / 6$ & $0 / 6$ & $0 / 6$ & $0 / 6$ & 500 & $5 d$ \\
\hline Vero/TMPRSS2 & $6 / 6$ & $6 / 6$ & $6 / 6$ & $6 / 6$ & $5 / 6$ & $0 / 6$ & $0 / 6$ & $0 / 6$ & 23.2 & $2 d$ \\
\hline Copies/reaction & 50,000 & 5000 & 500 & 50 & 5 & 0.5 & 0.05 & & & \\
\hline \multicolumn{11}{|l|}{ Real-time RT-PCR** } \\
\hline upE & 22.0 & 25.3 & 28.7 & 32.3 & 33.2 & $>40$ & $>40$ & $>40$ & 1.6 & $2 \mathrm{hr}$ \\
\hline ORF1a & 21.9 & 25.2 & 28.5 & 32.2 & 32.5 & $>40$ & $>40$ & $>40$ & 1.6 & $2 \mathrm{hr}$ \\
\hline RT-LAMP*** & 11.00 & 11.16 & 12.18 & 13.48 & 18.04 & 23.12 & $>30$ & $>30$ & 0.7 & $30 \mathrm{~min}$ \\
\hline
\end{tabular}

*Positive number/tested number.

***Threshold cycle.

***Time (min. s). 


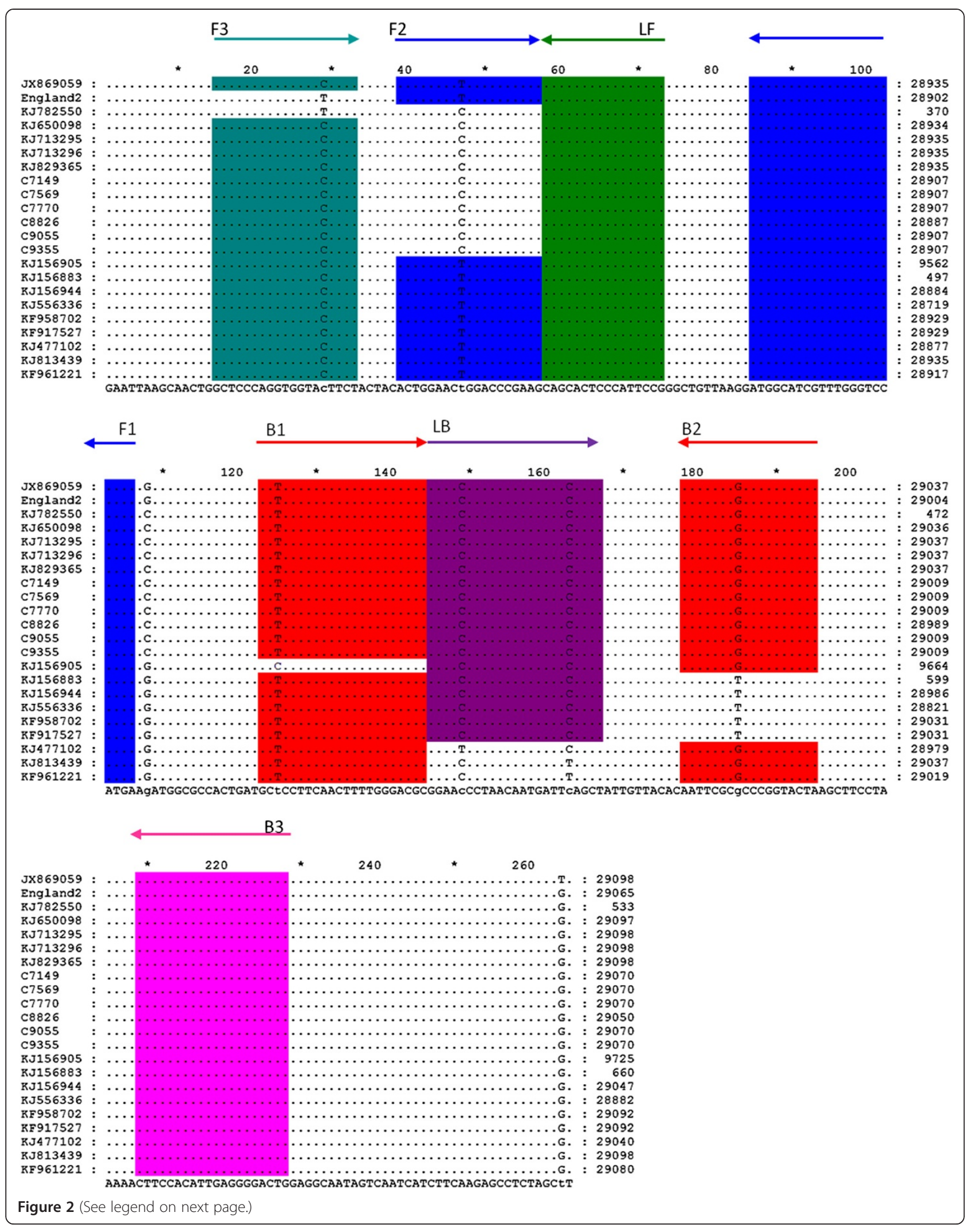


(See figure on previous page.)

Figure 2 Nucleotide mismatches in the MERS-CoV sequences. The MERS-CoV sequences that have mismatches with the RT-LAMP primer sets were identified in an alignment based on the sequence of the EMC isolate (JX869059.2). The positions of six essential regions (F3, F2, F1, B3, B2, and B1) and loop primers (LF and LB) are indicated. The accession numbers of the MERS-CoV sequences used in the alignment were as follows: JX869059, KJ782550, KJ650098, KJ713295, KJ713296, KJ829365, KJ156905, KJ156883, KJ156944, KJ556336, KF958702, KF917527, KJ477102, KJ813439 and KF961221. Seven MERS-CoV sequences available online (England2, Jeddah_2014_C7149, C7569, C7770, C8826, C9055 and C9355) were also used. The alignment was performed using GeneDoc ver. 2.7 (http://www.nrbsc.org/gfx/genedoc/).

reported online (England2-HPA, Jeddah_2014_C7149, C7569, C7770, C8826, C9055, and C9355]. An alignment was constructed using the EMC isolate and mismatched sequences (Figure 2). The RT-LAMP primers matched most of the 88 sequences. Primers B3 and LF matched them completely. Primer F3 had one nucleotide mismatch for two sequences. Primer LB had one nucleotide mismatch for one sequence and had another mismatch for two sequences. Primer BIP had one nucleotide mismatch in $\mathrm{B} 1$ region of one sequence and had another mismatch in the B2 region of five sequences. Primer FIP had a one-nucleotide mismatch in the F1 region of 11 sequences (Table 1). The efficiency of RTLAMP for these mismatched sequences was evaluated using an RNA template transcribed from a 1242-bp of PCR amplicon from the nucleocapsid gene sequence of MERS-CoV (Table 6). The sensitivity of RT-LAMP using the RNA control template of the EMC isolate was 15.8 copies and tended to be lower than that using viral RNA as the template. This might be caused by a difference in RT efficiency or the secondary structure of RNA due to the difference in length. The mismatches in the F3, F2, B1, and LB region did not markedly affect the amplification efficiency, and the sensitivity was equal to or twice that of the EMC isolate. The mismatch in the $\mathrm{B} 2$ region affected amplification slightly, and showed a fivefold decrease in the sensitivity (73.4 copies). This mismatch in B2 was seen in 5 sequences (KJ156883, KJ156944, KF556336, KF958702, and KF917527) of the 88 MERS$\mathrm{CoV}$ sequences checked in this study. Nevertheless, these results suggest that the RT-LAMP primer set facilitates amplification of the remaining 83 sequences to the same level as the EMC isolate.

\section{Discussion}

As described above, definitive MERS-CoV diagnosis requires amplification of at least two different virusspecific genomic targets according to the case definition reported on 3 July 2013 by the WHO. However, only two real-time RT-PCR targets, upE and ORF1a, are currently available for MERS-CoV detection with high specificity and sensitivity $[14,15]$. Indeed, two previous cases reported by the Italian government had to be reclassified as probable MERS-CoV infections, as they were unable to fulfill these criteria (WHO, GAR, MERS-CoV summary and literature update - as of 20 September 2013, http:// www.who.int/csr/disease/coronavirus_infections/update_ 20130920/en/index.html). Additional sensitive and specific genetic diagnostic methods are therefore needed to provide reliable MERS-CoV diagnoses.

This study describes a novel genetic diagnostic method for MERS-CoV based on the RT-LAMP assay, with a sensitivity and specificity equal to that of the upE and ORF1a RT-PCR assays. This assay was also able to detect MERS-CoV RNA in experimentally obtained nasopharyngeal swabs, and never showed cross reactivity to other respiratory viruses, even in the case of clinical specimens.

The RT-LAMP method requires only a single temperature for amplification, with results usually available in less than $1 \mathrm{~h}$ by observing magnesium pyrophosphate

Table 6 Evaluation of RT-LAMP amplification using mismatched sequences

\begin{tabular}{|c|c|c|c|c|c|}
\hline Accession & Name & & & & Sensitivity (copies) \\
\hline JX869059 & EMC & & & & 15.8 \\
\hline \multicolumn{2}{|c|}{ Representative sequence } & Nucleotide position $^{*}$ & Substitution & Region in primer & Sensitivity (copies) \\
\hline & England2 & 28862 & $C$ to $T$ & F3 & 7.3 \\
\hline \multirow[t]{2}{*}{ KJ782550 } & Greece-Saudi Arabia_2014 & 28862 & $C$ to $T$ & F3 & 15.8 \\
\hline & & 28880 & T to $C$ & FIP (F2) & \\
\hline KJ650098 & Camel/Qatar_2_2014 & 28880 & T to $C$ & FIP (F2) & 34.1 \\
\hline KJ156905 & Riyadh_7b_2013 & 28958 & T to $C$ & $\mathrm{BIP}(\mathrm{B} 1)$ & 15.8 \\
\hline KF917527 & Jeddah-Camel-1 & 29018 & $\mathrm{G}$ to $\mathrm{T}$ & $\mathrm{BIP}(\mathrm{B} 2)$ & 73.4 \\
\hline KJ477102 & NRCE-HKU205 & 28982 & $C$ to $T$ & LB & 39.7 \\
\hline KF961221 & Qatar3 & 28996 & $C$ to $T$ & LB & 7.3 \\
\hline
\end{tabular}

*Based on EMC isolate (JX869059.2). 
precipitate or fluorescence signals by the naked eye $[21,22]$. Although RT-LAMP amplification can be monitored in real-time using a turbidimeter [23], the assay can also be performed using basic laboratory equipment, such as a heat block and water bath. The method has been validated using various respiratory viruses, as well as more diverse pathogens, such as bacteria [33-35], protozoa [36-38], and parasites [39,40]. Furthermore, the reagents necessary to perform RT-LAMP are commercially available. Recently, Abd El Wahed et al., reported a genetic diagnostic method for MERS-CoV based on reverse transcription isothermal recombinase polymerase amplification (RT-PPA) assay. The method is highly sensitive and can detect 10 copies of virus RNA within 3 to 7 minutes. Therefore, it is useful for the diagnosis of MERS-CoV as well. However, RT-RPA requires a specific tubescanner for detection. By contrast, the RT-LAMP assay enables detection of amplicons by observing a magnesium pyrophosphate precipitate or fluorescence signals with the naked eye with no requirement for any specialized instruments. Taken together, the specificity and sensitivity of the RT-LAMP assay described here, in combination with its accessibility and ease of use, make this assay a valuable tool for the diagnosis and epidemiologic surveillance of human MERS-CoV infection, especially for field use.

The primer sets described in this study matched to most of the available sequences. However, several sequences had mismatches with the primers. The effect of these mismatches on the RT-LAMP efficiency was evaluated using a synthesized control RNA template: most of the mismatches did not affect the amplification efficiency of RT-LAMP. However, the substitution in B2 region of the primer, namely, a $\mathrm{G}$ to $\mathrm{T}$ substitution at position 29018 in the nucleocapsid gene sequence of the EMC isolate, was present in five MERS-CoV sequences and caused a slight decrease in sensitivity. Of the five sequences, KJ156883 (Asir_1_2013) belongs to the Buraidah_1 clade, and is the only sequence in this clade with such a substitution [41]. The other sequences (KJ156944, Riyadh_5_2013; KJ556336, Jeddah_1_2013; KF958702, Jeddah_human1; KF917527, Jeddah_Camel1) belong to the Riyadh_3 clade [42,43]; none of the other sequences in this clade have a substitution according to the alignment analysis. Therefore, the substitution does not represent a major population in this clade. Although it is important to improve the primers to increase their sensitivity for sequences in the Riyadh_3 clade by using mixed bases, the results of this study suggest that the RT-LAMP primer is useful for detecting the majority of the prevalent MERS-CoV strains.

The success rate of MERS-CoV detection is dependent on the collection of clinical specimens. Drosten et al., reported that up to $10^{6}$ copies/mL of MERS-CoV RNA are present in lower respiratory tract specimens, such as tracheobronchial secretions, and bronchoalveolar lavage. In contrast, only small amounts of viral RNAs were detected in upper respiratory tract specimens and other tissue [44]. The RT-LAMP primers described here were designed based upon the nucleocapsid protein sequence of MERS-CoV, due to the unique coronaviral replication system. Although coronaviruses generate subgenomic mRNAs to produce each viral protein, all subgenomic mRNAs contain nucleoprotein sequences, as they are located on the 3 'end of the coronavirus genome [45-47]. This implies that the RT-LAMP procedure described here will exhibit a high degree of sensitivity for specimens containing cellular components.

\section{Conclusions}

This study developed a RT-LAMP assay for the MERS$\mathrm{CoV}$, which was capable of detecting as few as 3.4 copies of MERS-CoV RNA, and was highly specific, with no cross-reaction with other respiratory viruses. These results suggest that the RT-LAMP assay described here is a useful tool for the diagnosis and epidemiologic surveillance of human MERS-CoV infections.

\section{Abbreviations \\ CoV: Coronavirus; FFU: Focus forming unit; MERS: Middle East respiratory syndrome; ORF: Open reading frame; PBS: Phosphate-buffered saline; PFU: Plaque forming unit; RT-LAMP: Reverse transcription-loop-mediated isothermal amplification; TCID50: 50\% tissue culture infectious dose; TMPRSS2: Transmembrane protease, serine 2; upE: Upstream E.}

\section{Competing interests}

The authors declare that they have no competing interests.

\section{Authors' contributions}

All authors participating in the planning of the project. SS and TsuN constructed the RT-LAMP primer set and evaluated the sensitivity. TY, SA, TK, and TaN participated in the pilot experiments. KS participated in all experiments and wrote manuscript. SM is the leader of the project. All authors read and approved the final manuscript.

\section{Acknowledgements}

We thank Dr. Ron A. M. Fouchier, Erasmus Medical Center, Rotterdam, The Netherlands for providing MERS-CoV EMC isolate. We also thank the staff of Mie Prefecture Health and Environment Research Institute, Mie, Japan. This work was supported by a grant-in-aid from the Ministry of Health, Labor, and Welfare, Japan. We thank Dr. Aiko Fukuma and Dr. Shuetsu Fukushi, Department of Virology I, National Institute of Infectious Diseases, Japan, for cloning of the nucleocapsid sequence of MERS-COV.

\section{Author details}

'Laboratory of Acute Respiratory Viral Diseases and Cytokines, Department of Virology III, National Institute of Infectious Disease, Laboratory of Acute Respiratory Viral Diseases and Cytokines, 4-7-1 Gakuen, Musashimurayama, Tokyo 208-0011, Japan. ${ }^{2}$ Mie Prefecture Health and Environment Research Institute, 3684-11 Sakura-cho, Yokkaichi, Mie 512-1211, Japan. ${ }^{3}$ Eiken Chemical Co. Ltd., 4-19-9 Taito, Taito-ku, Tokyo 110-8408, Japan.

Received: 25 April 2014 Accepted: 4 August 2014

Published: 8 August 2014 


\section{References}

1. Danielsson N, On Behalf Of The Ecdc Internal Response Team C, Catchpole M: Novel coronavirus associated with severe respiratory disease: case definition and public health measures. Euro Surveill 2012, 17:20282.

2. Zaki AM, van Boheemen S, Bestebroer TM, Osterhaus AD, Fouchier RA: Isolation of a novel coronavirus from a man with pneumonia in Saudi Arabia. N Engl I Med 2012, 367:1814-1820

3. de Groot RJ, Baker SC, Baric RS, Brown CS, Drosten C, Enjuanes L, Fouchier RA, Galiano M, Gorbalenya AE, Memish ZA, Perlman S, Poon LL, Snijder EJ, Stephens GM, Woo PC, Zaki AM, Zambon M, Ziebuhr J: Middle East respiratory syndrome coronavirus (MERS-CoV): announcement of the coronavirus study group. J Virol 2013, 87:7790-7792.

4. van Boheemen S, de Graaf M, Lauber C, Bestebroer TM, Raj VS, Zaki AM, Osterhaus AD, Haagmans BL, Gorbalenya AE, Snijder EJ, Fouchier RA: Genomic characterization of a newly discovered coronavirus associated with acute respiratory distress syndrome in humans. MBio 2012, 3:e00473-00412.

5. Peiris JS, Guan Y, Yuen KY: Severe acute respiratory syndrome. Nat Med 2004, 10:S88-97.

6. Li W, Shi Z, Yu M, Ren W, Smith C, Epstein JH, Wang H, Crameri G, Hu Z, Zhang H, Zhang J, McEachern J, Field H, Daszak P, Eaton BT, Zhang S, Wang LF: Bats are natural reservoirs of SARS-like coronaviruses. Science 2005, 310:676-679.

7. Lau SK, Li KS, Huang Y, Shek CT, Tse H, Wang M, Choi GK, Xu H, Lam CS, Guo R, Chan KH, Zheng BJ, Woo PC, Yuen KY: Ecoepidemiology and complete genome comparison of different strains of severe acute respiratory syndrome-related rhinolophus bat coronavirus in China reveal bats as a reservoir for acute, self-limiting infection that allows recombination events. J Virol 2010, 84:2808-2819.

8. Hemida MG, Perera RA, Wang P, Alhammadi MA, Siu LY, Li M, Poon LL, Saif L, Alnaeem A, Peiris M: Middle East respiratory syndrome (MERS) coronavirus seroprevalence in domestic livestock in Saudi Arabia, 2010 to 2013. Euro Surveill 2013, 18:20659.

9. Kupferschmidt K: Emerging diseases: researchers scramble to understand camel connection to MERS. Science 2013, 341:702.

10. Reusken C, Ababneh M, Raj V, Meyer B, Eljarah A, Abutarbush S, Godeke G, Bestebroer T, Zutt I, Muller M, Bosch B, Rottier P, Osterhaus A, Drosten C, Haagmans B, Koopmans M: Middle East respiratory syndrome coronavirus (MERS-CoV) serology in major livestock species in an affected region in Jordan, June to September 2013. Euro Surveill 2013, 18:20662.

11. Reusken CB, Haagmans BL, Muller MA, Gutierrez C, Godeke GJ, Meyer B, Muth D, Raj VS, Smits-De Vries L, Corman VM, Drexler JF, Smits SL, El Tahir YE, De Sousa R, van Beek J, Nowotny N, van Maanen K, Hidalgo-Hermoso E, Bosch BJ, Rottier P, Osterhaus A, Gortazar-Schmidt C, Drosten C, Koopmans MP: Middle East respiratory syndrome coronavirus neutralising serum antibodies in dromedary camels: a comparative serological study. Lancet Infect Dis 2013, 13:859-866.

12. Alagaili AN, Briese T, Mishra N, Kapoor V, Sameroff SC, Burbelo PD, de Wit E, Munster VJ, Hensley LE, Zalmout IS, Kapoor A, Epstein JH, Karesh WB, Daszak P, Mohammed OB, Lipkin Wl: Middle East respiratory syndrome coronavirus infection in dromedary camels in Saudi Arabia. MBio 2014, 5:e00884-00814

13. Haagmans BL, Al Dhahiry SH, Reusken CB, Raj VS, Galiano M, Myers R, Godeke GJ, Jonges M, Farag E, Diab A, Ghobashy H, Alhaji F, Al-Thani M, Al-Marri SA, Al Romaihi HE, Al Khal A, Bermingham A, Osterhaus AD, AlHaji MM, Koopmans MP: Middle East respiratory syndrome coronavirus in dromedary camels: an outbreak investigation. Lancet Infect Dis 2014, 14:140-145.

14. Corman V, Eckerle I, Bleicker T, Zaki A, Landt O, Eschbach-Bludau M, van Boheemen S, Gopal R, Ballhause M, Bestebroer T, Muth D, Muller M, Drexler J, Zambon M, Osterhaus A, Fouchier R, Drosten C: Detection of a novel human coronavirus by real-time reverse-transcription polymerase chain reaction. Euro Surveill 2012, 17:20285.

15. Corman VM, Muller MA, Costabel U, Timm J, Binger T, Meyer B, Kreher $P$, Lattwein E, Eschbach-Bludau M, Nitsche A, Bleicker T, Landt O, Schweiger B, Drexler JF, Osterhaus AD, Haagmans BL, Dittmer U, Bonin F, Wolff T, Drosten C: Assays for laboratory confirmation of novel human coronavirus (hCoV-EMC) infections. Euro Surveill 2012, 17:20334.

16. Chen W, He B, Li C, Zhang X, Wu W, Yin X, Fan B, Fan X, Wang J: Real-time RT-PCR for H5N1 avian influenza A virus detection. J Med Microbiol 2007, 56:603-607.
17. Pang $X$, Lee B, Chui L, Preiksaitis JK, Monroe SS: Evaluation and validation of real-time reverse transcription-pcr assay using the LightCycler system for detection and quantitation of norovirus. J Clin Microbiol 2004, 42:4679-4685.

18. Ke GM, Cheng HL, Ke LY, Ji WT, Chulu JL, Liao MH, Chang TJ, Liu HJ: Development of a quantitative light cycler real-time RT-PCR for detection of avian reovirus. J Virol Methods 2006, 133:6-13.

19. Yan L, Yan P, Zhou J, Teng Q, Li Z: Establishing a TaqMan-based real-time PCR assay for the rapid detection and quantification of the newly emerged duck Tembusu virus. Virol J 2011, 8:464.

20. Parida MM: Rapid and real-time detection technologies for emerging viruses of biomedical importance. J Biosci 2008, 33:617-628.

21. Notomi T, Okayama H, Masubuchi $\mathrm{H}$, Yonekawa T, Watanabe K, Amino N, Hase T: Loop-mediated isothermal amplification of DNA. Nucleic Acids Res 2000, 28:E63.

22. Nagamine K, Hase T, Notomi T: Accelerated reaction by loop-mediated isothermal amplification using loop primers. Mol Cell Probes 2002, 16:223-229.

23. Mori Y, Nagamine K, Tomita N, Notomi T: Detection of loop-mediated isothermal amplification reaction by turbidity derived from magnesium pyrophosphate formation. Biochem Biophys Res Commun 2001, 289:150-154.

24. Hong TC, Mai OL, Cuong DV, Parida M, Minekawa H, Notomi T, Hasebe F, Morita K: Development and evaluation of a novel loop-mediated isothermal amplification method for rapid detection of severe acute respiratory syndrome coronavirus. J Clin Microbiol 2004, 42:1956-1961.

25. Shirato K, Nishimura H, Saijo M, Okamoto M, Noda M, Tashiro M, Taguchi F: Diagnosis of human respiratory syncytial virus infection using reverse transcription loop-mediated isothermal amplification. $J$ Virol Methods 2007, 139:78-84.

26. Ushio M, Yui I, Yoshida N, Fujino M, Yonekawa T, Ota Y, Notomi T, Nakayama T: Detection of respiratory syncytial virus genome by subgroups-A, B specific reverse transcription loop-mediated isothermal amplification (RT-LAMP). J Med Virol 2005, 77:121-127.

27. Imai M, Ninomiya A, Minekawa H, Notomi T, Ishizaki T, Tashiro M, Odagiri T: Development of H5-RT-LAMP (loop-mediated isothermal amplification) system for rapid diagnosis of $\mathrm{H} 5$ avian influenza virus infection. Vaccine 2006, 24:6679-6682.

28. Mahony J, Chong S, Bulir D, Ruyter A, Mwawasi K, Waltho D: Multiplex loop-mediated isothermal amplification (M-LAMP) assay for the detection of influenza $\mathrm{A} / \mathrm{H} 1, \mathrm{~A} / \mathrm{H} 3$ and influenza $\mathrm{B}$ can provide a specimen-to-result diagnosis in $40 \mathrm{~min}$ with single genome copy sensitivity. J Clin Virol 2013, 58:127-131.

29. Shirato K, Kawase M, Watanabe O, Hirokawa C, Matsuyama S, Nishimura $H$, Taguchi F: Differences in neutralizing antigenicity between laboratory and clinical isolates of HCoV-229E isolated in Japan in 2004-2008 depend on the S1 region sequence of the spike protein. J Gen Virol 2012, 93:1908-1917

30. Shirogane Y, Takeda M, Iwasaki M, Ishiguro N, Takeuchi H, Nakatsu Y, Tahara M, Kikuta H, Yanagi Y: Efficient multiplication of human metapneumovirus in Vero cells expressing the transmembrane serine protease TMPRSS2. J Virol 2008, 82:8942-8946.

31. Gierer S, Bertram S, Kaup F, Wrensch F, Heurich A, Kramer-Kuhl A, Welsch K, Winkler M, Meyer B, Drosten C, Dittmer U, von Hahn T, Simmons G, Hofmann $H$, Pohlmann S: The spike protein of the emerging betacoronavirus EMC uses a novel coronavirus receptor for entry, can be activated by TMPRSS2, and is targeted by neutralizing antibodies. J Virol 2013, 87:5502-5511

32. Shirato K, Kawase M, Matsuyama S: Middle East respiratory syndrome coronavirus infection mediated by the transmembrane serine protease TMPRSS2. J Virol 2013, 87:12552-12561.

33. Ueda S, Kuwabara Y: The rapid detection of Salmonella from food samples by loop-mediated isothermal amplification (LAMP). Biocontrol Sci 2009, 14:73-76.

34. Geojith G, Dhanasekaran S, Chandran SP, Kenneth J: Efficacy of loop mediated isothermal amplification (LAMP) assay for the laboratory identification of Mycobacterium tuberculosis isolates in a resource limited setting. J Microbiol Methods 2011, 84:71-73.

35. Gotoh K, Nishimura N, Ohshima Y, Arakawa Y, Hosono H, Yamamoto Y, Iwata Y, Nakane K, Funahashi K, Ozaki T: Detection of Mycoplasma pneumoniae by loop-mediated isothermal amplification (LAMP) assay 
and serology in pediatric community-acquired pneumonia. J Infect Chemother 2012, 18:662-667.

36. Plutzer J, Karanis P: Rapid identification of Giardia duodenalis by loop-mediated isothermal amplification (LAMP) from faecal and environmental samples and comparative findings by PCR and real-time PCR methods. Parasitol Res 2009, 104:1527-1533.

37. He L, Zhou YQ, Oosthuizen MC, Zhao JL: Loop-mediated isothermal amplification (LAMP) detection of Babesia orientalis in water buffalo (Bubalus babalis, Linnaeus, 1758) in China. Vet Parasitol 2009, 165:36-40.

38. Wang $L X$, He L, Fang $R$, Song QQ, Tu P, Jenkins A, Zhou YQ, Zhao JL: Loop-mediated isothermal amplification (LAMP) assay for detection of Theileria sergenti infection targeting the p33 gene. Vet Parasitol 2010, 171:159-162.

39. Nakao R, Stromdahl EY, Magona JW, Faburay B, Namangala B, Malele I, Inoue N, Geysen D, Kajino K, Jongejan F, Sugimoto C: Development of loop-mediated isothermal amplification (LAMP) assays for rapid detection of Ehrlichia ruminantium. BMC Microbiol 2010, 10:296.

40. Arimatsu Y, Kaewkes S, Laha T, Hong SJ, Sripa B: Rapid detection of Opisthorchis viverrini copro-DNA using loop-mediated isothermal amplification (LAMP). Parasitol Int 2012, 61:178-182.

41. Cotten M, Watson SJ, Zumla Al, Makhdoom HQ, Palser AL, Ong SH, Al Rabeeah AA, Alhakeem RF, Assiri A, Al-Tawfiq JA, Albarrak A, Barry M, Shibl A, Alrabiah FA, Hajjar S, Balkhy HH, Flemban H, Rambaut A, Kellam P, Memish ZA: Spread, circulation, and evolution of the Middle East respiratory syndrome coronavirus. MBio 2014, 5:e01062-01013.

42. Azhar El, El-Kafrawy SA, Farraj SA, Hassan AM, Al-Saeed MS, Hashem AM, Madani TA: Evidence for camel-to-human transmission of MERS coronavirus. N Engl J Med 2014, 370:2499-2505.

43. Memish ZA, Cotten M, Meyer B, Watson SJ, Alsahafi AJ, Al Rabeeah AA, Corman VM, Sieberg A, Makhdoom HQ, Assiri A, Al Masri M, Aldabbagh S, Bosch BJ, Beer M, Muller MA, Kellam P, Drosten C: Human infection with MERS coronavirus after exposure to infected camels, Saudi Arabia, 2013. Emerg Infect Dis 2014, 20:1012-1015.

44. Drosten C, Seilmaier M, Corman VM, Hartmann W, Scheible G, Sack S, Guggemos W, Kallies R, Muth D, Junglen S, Muller MA, Haas W, Guberina H, Rohnisch T, Schmid-Wendtner M, Aldabbagh S, Dittmer U, Gold H, Graf P, Bonin F, Rambaut A, Wendtner CM: Clinical features and virological analysis of a case of Middle East respiratory syndrome coronavirus infection. Lancet Infect Dis 2013, 13:745-751.

45. Baric RS, Stohlman SA, Lai MM: Characterization of replicative intermediate RNA of mouse hepatitis virus: presence of leader RNA sequences on nascent chains. J Virol 1983, 48:633-640.

46. Lai MM, Patton CD, Baric RS, Stohlman SA: Presence of leader sequences in the mRNA of mouse hepatitis virus. J Virol 1983, 46:1027-1033.

47. Spaan WJ, Rottier PJ, Horzinek MC, van der Zeijst BA: Sequence relationships between the genome and the intracellular RNA species 1, 3,6 , and 7 of mouse hepatitis virus strain A59. J Virol 1982, 42:432-439.

\section{Submit your next manuscript to BioMed Central and take full advantage of:}

- Convenient online submission

- Thorough peer review

- No space constraints or color figure charges

- Immediate publication on acceptance

- Inclusion in PubMed, CAS, Scopus and Google Scholar

- Research which is freely available for redistribution 